\title{
Toxicologic effects of gold nanoparticles in vivo by different administration routes
}

This article was published in the following Dove Press journal:

International Journal of Nanomedicine

25 September 2010

Number of times this article has been viewed

\author{
Xiao-Dong Zhang* \\ Hong-Ying Wu* \\ DiWu \\ Yue-Ying Wang \\ Jian-Hui Chang \\ Zhi-Bin Zhai \\ Ai-Min Meng \\ Pei-Xun Liu \\ Liang-An Zhang \\ Fei-Yue Fan \\ Institute of Radiation Medicine, \\ Chinese Academy of Medical \\ Sciences and Peking Union Medical \\ College, and Tianjin Key Laboratory \\ of Molecular Nuclear Medicine. \\ Tianjin, People's Republic of China \\ *The authors contributed equally to \\ this work
}

Correspondence: X-D Zhang Institute of Radiation Medicine, Chinese Academy of Medical Sciences, and Peking Union Medical College, No.238, Baidi Road, Nankai District. Tianjin, 300I92, P.R. China

Tel +86-22-85683I73

Email xiaodongzhang@yahoo.cn;

ai_min_meng@I26.com;

Faithfan@yahoo.cn

\begin{abstract}
Gold nanoparticles have potential applications in biomedicine, but one of the important concerns is about their safety. Most toxicology data are derived from in vitro studies and may not reflect in vivo responses. Here, an animal toxicity study of $13.5 \mathrm{~nm}$ gold nanoparticles in mice is presented. Animal survival, weight, hematology, morphology, and organ index are characterized at different concentrations $(137.5-2200 \mu \mathrm{g} / \mathrm{kg})$ over 14-28 days. The results show that low concentrations of gold nanoparticles do not cause an obvious decrease in body weight or appreciable toxicity, even after their breakdown in vivo. High concentrations of gold nanoparticles induced decreases in body weight, red blood cells, and hematocrit. It was also found that gold nanoparticles administered orally caused significant decreases in body weight, spleen index, and red blood cells. Of the three administration routes, the oral and intraperitoneal routes showed the highest toxicity, and the tail vein injection showed the lowest toxicity. Combining the results of all of these studies, we suggest that targeted gold nanopartices by tail vein injection may be suitable for enhancement of radiotherapy, photothermal therapy, and related medical diagnostic procedures.
\end{abstract}

Keywords: gold nanoparticles, in vivo, toxicity

\section{Introduction}

Colloidal gold nanoparticles have been proposed for diverse biomedical applications due to their unique surface, electronic, and optical properties. ${ }^{1,2}$ Because of the strong and size-tunable surface plasmon resonance, fluorescence, and easy-surface functionalization, gold nanoparticles have been widely used in biosensors, cancer cell imaging, photothermal therapy, and drug delivery. ${ }^{3-9}$ Today, gold nanoparticles have been suggested to be potentially useful as a novel radiosensitizer in radiotherapy, because the strong photoelectric absorption and secondary electron caused by gamma or X-ray irradiation can accelerate DNA strand breaks. ${ }^{10-12}$ However, the potential toxicity of gold nanoparticles is still not completely understood.

In the past few years, the toxicity of nanomaterials, such as nanoparticles, quantum dots, nanowires, and nanotubes has been reported. ${ }^{13-18}$ In general, the toxicity of gold nanoparticles depends on their physical dimensions (such as size and shape) and surface chemistry (such as coating). The biosafety of metallic gold is well recognized and it has been used in vivo since the 1950s. However, functionalized gold nanoparticles show obvious cytotoxicity. ${ }^{19}$ To clarify these problems, the cytotoxicity of gold nanoparticles in human cells has been studied in detail, and the results have shown that gold nanoparticles are nontoxic up to $250 \mathrm{mM}$, while ionic gold shows obvious cytotoxicity at $25 \mathrm{mM} .{ }^{20}$ Similar results were also reported recently using gold nanoparticles as 
radiotherapy in vitro. ${ }^{21-28}$ Despite these in vitro studies, there are few toxicologic reports of gold nanoparticles in animal models, which is the preferred system for toxicologic evaluation of a novel agent and should be used to characterize the toxicity of gold nanoparticles. Actually, in vitro cultures cannot replicate the complexity of an in vivo system or provide meaningful data about the response of a physiologic system to an agent. A case in point is carbon nanotubes. ${ }^{29}$ Manna et al found toxicity in vitro, whereas Schipper et al found no significant toxicity in vivo. $3^{0}$ Similarly, Sayes et al found that in vivo toxicology results for fullerenes were very different from in vitro data. ${ }^{31}$ The toxicity in vivo is determined by many parameters including dose, route of exposure, metabolism, excretion, and immune response. The toxicologic profiles of nanomaterials might also be determined by nanomaterial chemical composition, size, shape, aggregation, and surface coating.

Very recently, the size-dependent organ distributions of gold nanoparticles have been investigated, and the results showed that small gold nanoparticles of 5-15 $\mathrm{nm}$ had wider organ distribution than that of large gold nanoparticles of 50-100 nm, and liver and spleen were the dominant targeted organs. ${ }^{32-37}$ Meanwhile, it has been found that gold nanoparticles with a long blood circulation time can accumulate in the liver and spleen, and have obvious effects on gene expression. ${ }^{38-40}$ Furthermore, the toxicity and biodistribution of polyethylene glycol (PEG)-coated gold nanoparticles have also been investigated, and the results showed that 20 nm gold nanoparticles coated with TA-terminated PEG $_{5000}$ was more stable and had lower toxicity than $20 \mathrm{~nm}, 40 \mathrm{~nm}$, or $80 \mathrm{~nm}$ gold nanoparticles coated with TA-terminated $\mathrm{PEG}_{5000}{ }^{36,38,41,42}$ These in vivo results demonstrated that the possible toxicity of gold nanoparticles could occur in the body over short- and middle-term injection, and further toxicologic investigations and biologic changes are necessary in vivo.

In previous work we have evaluated the irradiation stability and cytotoxicity of gold nanoparticles. ${ }^{43}$ Here, we carry out a toxicologic study of gold nanoparticles by using three different injected routes, namely oral, intraperitoneal, and tail vein injection. Gold nanoparticles of $13.5 \mathrm{~nm}$ with well-known good biocompatibility were chosen for this work. This experimental model can be applied to other engineered nanostructures, such as metallic nanoparticles, and the outcome of these studies will determine which injection route may be more suitable for photothermal therapy and radiotherapy. Furthermore, the related hematologic parameters of organs have been analyzed.

\section{Materials and methods}

\section{Fabrication of gold nanoparticles}

The gold nanoparticles in Figure 1 were fabricated following the classical method introduced by Turkevich et al. ${ }^{44} \mathrm{~A}$ volume of $100 \mathrm{~mL}$ of $0.01 \%$ chlorauric acid $\left(\mathrm{HAuCl}_{4} \cdot 4 \mathrm{H}_{2} \mathrm{O}\right)$ solution is refluxed, and $5 \mathrm{~mL}$ of $1 \%$ sodium citrate solution is added to the boiling solution. Reduction of gold ions by the citrate ions is completed after five minutes, and the solution is further boiled for 30 minutes and then left to cool to room temperature. This method yields spherical particles with an average diameter of about 13.5 $\mathrm{nm}$. Although the actual value of the mean size might vary slightly from each preparation, the size distribution is always found to have a standard deviation of about $12 \%$. Subsequently, the $\mathrm{pH}$ value of the citrate-coated gold nanoparticle solution is adjusted to 7.4 using dilute $\mathrm{NaOH}$ buffer solution, which is close to the physiologic environment of mice. The citrate-coated gold nanoparticle solution is filtered through $0.45 \mu \mathrm{m}$ filters to remove the precipitate, and the filtrate can be stored at $4{ }^{\circ} \mathrm{C}$ in order to prevent aggregation. The gold nanoparticle suspension $(1 \mathrm{~mL})$ is centrifuged at $13,500 \mathrm{rpm}$ for 20 minutes, and the supernatant is removed. The remaining gold nanoparticles are resuspended in $1 \mathrm{~mL}$ of ultrapure water, and gold nanoparticles with different concentrations can be obtained.

The size and morphology of the gold nanoparticles were analyzed by transmission electron microscopy using a Hitachi HF-2000 field emission high-resolution transmission electron microscopy operating at $200 \mathrm{kV}$. The optical absorption spectra in the wavelength range of $200-850 \mathrm{~nm}$ was measured using a DU800 spectrometer in a $5 \mathrm{~mL}$ glass cuvette.

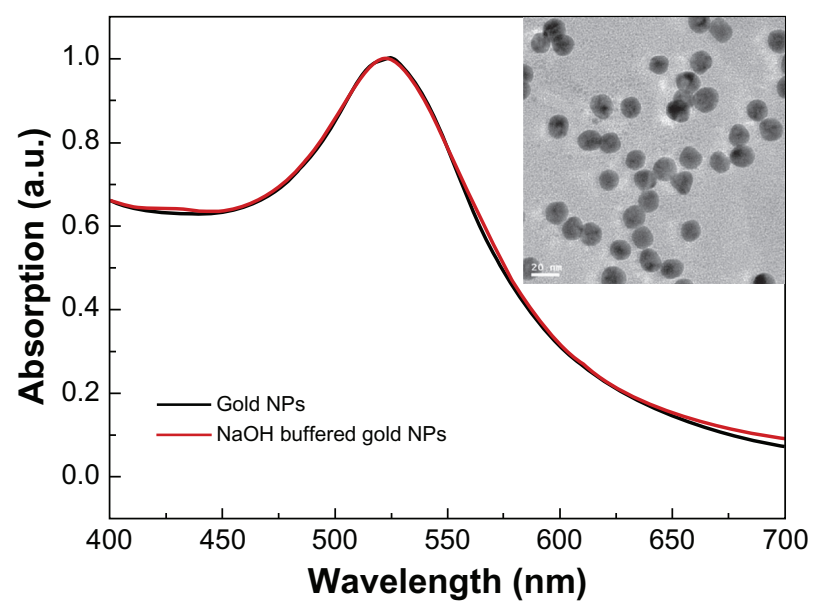

Figure I Size and morphology of gold nanoparticles. The ultraviolet spectra of gold nanoparticles and transmission electron microscopic analysis (figure inset).

Note: Gold nanoparticles were synthesized following the procedure described by Turkevich et al. ${ }^{30}$ 


\section{Experimental design}

Animals were purchased, maintained, and handled using protocols approved by the Institute of Radiation Medicine at the Chinese Academy of Medical Sciences. Male ICR mice were obtained from the Institute of Radiation Medicine laboratories at 11 weeks of age, were housed in a 12 hour/12 hour light/dark cycle, and given food and water ad libitum. In the concentration-dependent toxicologic experiment, 36 mice were randomly divided into six groups (six in each group), comprising one control group and five experimental groups allocated to different doses of gold nanoparticles. Mice received oral administration of approximately $200 \mu \mathrm{L}$ of gold nanoparticle solution at doses of $137.5 \mu \mathrm{g} / \mathrm{mL}, 275 \mu \mathrm{g} / \mathrm{mL}$, $550 \mu \mathrm{g} / \mathrm{mL}, 1100 \mu \mathrm{g} / \mathrm{mL}$, and $2200 \mu \mathrm{g} / \mathrm{mL}$, respectively. After daily injection, the mice were weighed and assessed for behavioral changes, and were sacrificed after injection of gold nanoparticles for 14 days.

Subsequently, the toxicologic experiments using the different administration methods were performed at a dose of $1100 \mu \mathrm{g} / \mathrm{mL}$. Thirty-six mice were randomly divided into six groups, comprising three kinds of administration and their respective control groups (six in each group). Administration to the mice was performed using oral, intraperitoneal, and tail vein injection. Mice were injected with $200 \mu \mathrm{L}$ of gold nanoparticle solution and physiologic saline (contrast groups). Every two days after injection, mice were weighed and assessed for behavioral changes. The injections were well tolerated and no adverse effects were observed during the 24-hour observation period. Mice were sacrificed after injection of gold nanoparticles for 28 days.

\section{Hematology and sample collection}

Using a standard saphenous vein blood collection technique, blood was drawn for hematology analysis (using potassiumethylenediaminetetraacetic acid collection tubes). Standard hematologic analysis was performed. For blood analysis, $300 \mu \mathrm{L}$ of blood was collected from the mice. At 14 and 28 days, mice were sacrificed using isoflurane anesthetic and angiocatheter exsanguination with phosphate-buffered saline. One mouse from each group was fixed with $10 \%$ buffered formalin following phosphate-buffered saline exsanguination. During necropsy, liver, kidneys, spleen, heart, lungs, brain, colon (section $10 \mathrm{~mm}$ in length), muscle (5 $\mathrm{mm}$ in diameter), thyroid, lymph nodes, and bone marrow (from the femur) were collected and weighed. The liver, kidneys, spleen, bone marrow, and lymph nodes were sectioned from the fixed mice.
Microscopic properties of gold nanoparticles in the bone marrow and blood cells were obtained after oral administration for 14 days at a dose of $2200 \mu \mathrm{g} / \mathrm{mL}$. For the transmission electron microscopy analysis, the solution was centrifuged and the pellet was fixed with $2.5 \%$ glutaraldehyde in $0.03 \mathrm{M}$ potassium phosphate buffer at $\mathrm{pH}$ 7.4. The cells are then fixed with $1 \%$ osmium tetroxide in $0.1 \mathrm{M}$ sodium cacodylate buffer and $0.5 \%$ uranyl acetate in $0.05 \mathrm{M}$ maleate buffer. Cells were then dehydrated in a graded series of ethanol and embedded in Epon. Ultrathin sections were cut and transferred on 200-mesh uncoated copper grids, stained with uranyl acetate, counterstained with lead citrate, and observed with Hitachi HF-2000 field emission high-resolution transmission electron microscopy operating at $200 \mathrm{kV}$.

\section{Results and discussion Effects on body weight}

Figure 2 shows the body weight variations of the mice after oral administration at different concentrations. It can be seen that oral administration of gold nanoparticles in the dose range $137.5-275 \mu \mathrm{g} / \mathrm{kg}$ did not cause mortality, and body weight was slightly higher compared with the control group during a one-day observation period. At the dose range of $550-2200 \mu \mathrm{g} / \mathrm{kg}$, the body weight of the mice was slightly but significantly lower than in the control group. During the study period, treatment with gold nanoparticles for 14 days did not cause obvious adverse effects on growth because no statistically significant differences in body weight gain were observed between the gold nanoparticle-treated mice

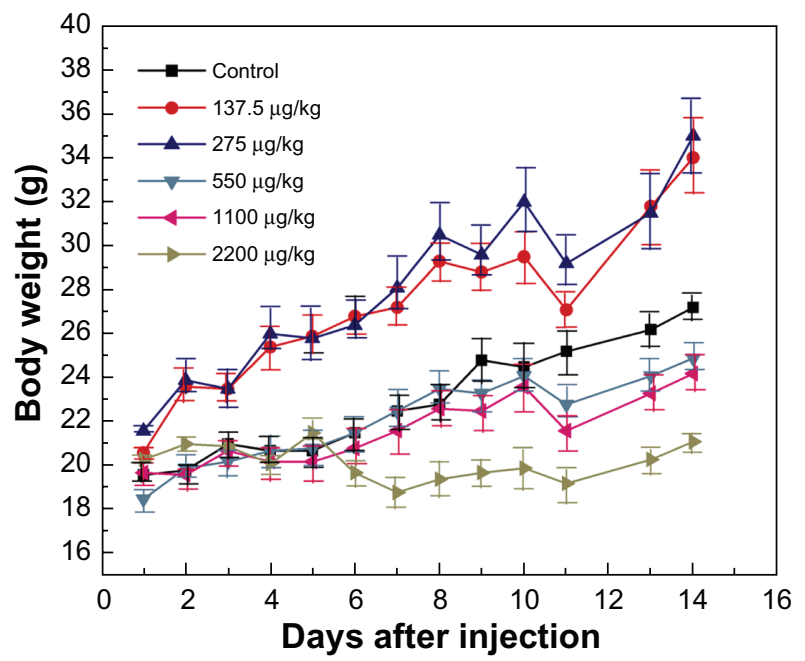

Figure 2 Body weight changes for mice treated with gold nanoparticles at doses of $137.5-2200 \mu \mathrm{g} / \mathrm{kg}$.

Note: Body weight was measured every two days. Each point represents the mean \pm standard deviation of six mice. Data were analyzed by Student's t-test and the differences between the doses and control group for each organ are not significant $(P>5 \%)$. 
and control mice. Furthermore, no abnormal clinical signs or behavior were detected in either the control or treated groups. Considered together, gold nanoparticle treatment did not induce any apparent toxicity in mice. Necropsy at the end of the experiment did not show any macroscopic organ changes in the six groups. It should be noted, however, that injection of gold nanoparticles caused transient reversible changes in body weight of the mice within 10-14 days after injection. Adverse vascular or behavioral reactions were not observed.

Body weight variation within 28 days at a dose of $1100 \mu \mathrm{g} / \mathrm{kg}$ is shown in Figure 3. It can be seen that body weight after tail vein injection was slightly decreased compared with the control group, and no statistically significant differences were observed by tail vein injection, which indicates low toxicity of gold nanoparticles via this route. Intraperitoneal injection induced a slight decrease in body weight, and oral administration showed an obvious effect on body weight. Statistical differences were observed for both intraperitoneal injection and oral administration. The decrease in body weight after oral administration was particularly obvious after 15 days of injection compared with that after 1-14 days. Therefore, the oral and intraperitoneal injections may induce some toxicity, while the tail vein injection may induce lower toxicity.

It is well known that size, shape, and surface capping (or modification) of nanoparticles can induce a different toxicity effect in mice. However, the toxicologic effect of the different administration routes is still not clear. Oral administration

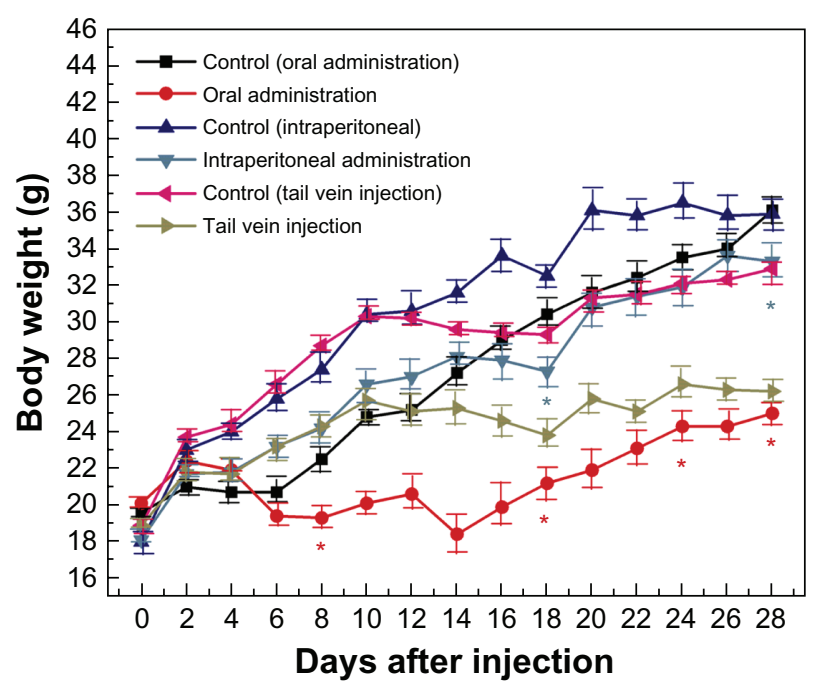

Figure 3 Body weight changes in mice treated with gold nanoparticles $1100 \mu g / k g$ by using three administration routes, ie, oral, intraperitoneal, and tail vein injection. Note: Each point represents mean \pm standard deviation. Data were analyzed by Student's t-test. *Represents significant difference from the control group $(P<0.05)$. may cause some effects on the digestive system, while tail vein injection mainly acts on blood and related organs. Indeed, previous toxicity investigations also showed that gold nanoparticles after oral administration had strong gastrointestinal persorption effects. ${ }^{45}$ It has been shown that oral delivery of nanoparticles may affect the mucosa due to the morphologic and physiologic absorption barriers in the gastrointestinal tract. ${ }^{46}$ In our experiment, no significant damage to the stomach was found, which indicates good absorption and digestion after gold nanoparticle injection. However, slight damage to the intestine, such as intestinal tympanites, was observed in two of six orally injected mice, which may be the main reason for the high toxicity of the gold nanoparticles. Therefore, the gastrointestinal reaction and absorption would play an important role in oral administration of gold nanoparticles. Intraperitoneal injection is generally preferred when intravenous injection is not feasible. It is well known that drug absorption by intraperitoneal injection is good and rapid due to the dense blood vessels and lymph in the murine peritoneum. Indeed, we found that the effect on body weight by intraperitoneal injection was less than that by oral administration.

Most recently, intraperitoneal injection of gold nanoparticles has been investigated by Lasagna-Reeves et al and the results showed toxicity was low at the dose range $320-3200 \mu \mathrm{g} / \mathrm{kg} /$ day. ${ }^{47}$ No evidence of toxicity was observed in any of the diverse studies, including survival, behavior, animal weight, organ morphology, blood biochemistry, and histology. However, it should be noticed that the toxicologic reactions in their experiments were carried out by consecutive injections (40-400 $\mu \mathrm{g} / \mathrm{kg} /$ day) ${ }^{47}$ Overall, gold nanoparticles by intraperitoneal injection were less toxic than oral administration at the dose of $1100 \mu \mathrm{g} / \mathrm{kg}$. Tail vein injection is widely used to study the toxicologic effects of gold nanoparticles (see Table 1). The benefit of performing a tail vein injection is that it is a less invasive procedure for the animal. We found that the lowest toxicity of the gold nanoparticles was associated with the tail vein injection. The previous biodistribution and pharmacokinetics of pegylated gold nanoparticles also showed the highest colloidal stability, nonaggregation, and lack of toxicity of $20 \mathrm{~nm}$ PEG-coated gold nanoparticles. ${ }^{41}$ Meanwhile, recent work by Cho et al showed that $13 \mathrm{~nm}$ PEG-coated gold nanoparticles could induce acute inflammation and apoptosis in the liver, and these nanoparticles were found to accumulate in the liver and spleen for up to seven days after tail vein injection and to have long blood circulation times. ${ }^{38}$ Cho et al showed that gold nanoparticles induced potential long-time organ 
Table I A summary of in vivo toxicity of gold nanoparticles

\begin{tabular}{|c|c|c|c|c|c|}
\hline Group & Surface coating & Size & Study period & Dose & $\begin{array}{l}\text { Method of } \\
\text { administration }\end{array}$ \\
\hline Hillyer ${ }^{45}$ & Naked & $4,10,28$, and $58 \mathrm{~nm}$ & 7 days & $20,000 \mu \mathrm{g} / \mathrm{kg}$ & Oral \\
\hline Hainfeld ${ }^{10}$ & PBS buffered & $1.9 \mathrm{~nm}$ & $5 \mathrm{~min}$ & $1350 \mu \mathrm{g} / \mathrm{kg}$ & Tail vein \\
\hline de Jong ${ }^{32}$ & Naked & $10,50,100$, and $250 \mathrm{~nm}$ & 24 hours & $77-120 \mu g / k g$ & Tail vein \\
\hline Sonavane $\mathrm{e}^{33}$ & Naked & $15,50,100$, and $200 \mathrm{~nm}$ & 24 hours & $1000 \mu \mathrm{g} / \mathrm{kg}$ & Tail vein \\
\hline $\mathrm{Kim}^{34}$ & PBS buffered & 20 and $100 \mathrm{~nm}$ & 24 hours & $1000 \mu \mathrm{g} / \mathrm{kg}$ & Tail vein \\
\hline Chen $^{35}$ & Naked & $\begin{array}{l}3,5,8,12,17,37 \text {, } \\
\text { and } 50 \mathrm{~nm}\end{array}$ & 21 days & $8000 \mu \mathrm{g} / \mathrm{g} /$ week & Intraperitoneal \\
\hline $\mathrm{Cho}^{36,38}$ & HS-PEG & 4,13 , and $100 \mathrm{~nm}$ & 4-30 min, I-7 days & $170-4200 \mu g / k g$ & Tail vein \\
\hline Semmler-Behnke ${ }^{37}$ & Naked & 1.4 and $18 \mathrm{~nm}$ & $24 \mathrm{~h}$ & $54-530 \mu g / k g$ & $\begin{array}{l}\text { Intratracheal } \\
\text { and intravenous }\end{array}$ \\
\hline Balasubramanian ${ }^{39}$ & Naked & $20 \mathrm{~nm}$ & $\begin{array}{l}\text { I day, I week, } \\
\text { I and } 2 \text { months }\end{array}$ & $10 \mu g / \mathrm{kg}$ & Intravenous \\
\hline Zhang' & PEG-TA or PEG-SH & 20,40 , and $80 \mathrm{~nm}$ & $48 \mathrm{~h}$ & $100-4400 \mu g / k g$ & Tail vein \\
\hline Lipka $^{42}$ & PEG & $5 \mathrm{~nm}$ & $\mathrm{I}-24 \mathrm{~h}$ & $570-870 \mu g / k g$ & $\begin{array}{l}\text { Tail vein and } \\
\text { intratracheal }\end{array}$ \\
\hline Lasagna-Reeves $^{47}$ & Naked & $12.5 \mathrm{~nm}$ & 8 days & $40-400 \mu \mathrm{g} / \mathrm{kg} / \mathrm{day}$ & Intraperitoneal \\
\hline Sadauskas ${ }^{50}$ & Naked & $40 \mathrm{~nm}$ & $\begin{array}{l}\text { Iday, I, 3, } \\
\text { and } 6 \text { months }\end{array}$ & $1400-1600 \mu g / \mathrm{kg}$ & Tail vein \\
\hline Fent $^{53}$ & $\begin{array}{l}\text { Gum arabic- and } \\
\text { maltose-coated }\end{array}$ & $6-10$ and $15-20 \mathrm{~nm}$ & $\begin{array}{l}\text { I-24 hours and } \\
7-32 \text { days }\end{array}$ & $2000 \mu \mathrm{g} / \mathrm{kg}$ & Intravenous \\
\hline This work & Naked & $13.5 \mathrm{~nm}$ & 14,28 days & 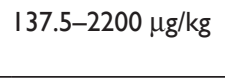 & $\begin{array}{l}\text { Tail vein, oral, } \\
\text { intraperitoneal }\end{array}$ \\
\hline
\end{tabular}

Abbreviations: PEG, polyethylene glycol; PBS, phosphate-buffered saline.

damage and toxicity, ${ }^{38}$ and their overall results showed that the toxicity by tail vein injection was the lowest among the three injection routes.

\section{Morphology of gold nanoparticles in blood and bone marrow cells}

Figure 4 shows transmission electron microscopy images of the gold nanoparticles in blood and bone marrow cells after oral administration of $2200 \mu \mathrm{g} / \mathrm{kg}$ for 14 days. For a single cell, multiple vesicles containing gold nanoparticles were readily observed. Within the vesicles, the gold nanoparticles appeared to be monodispersed, which is consistent with previous investigations. ${ }^{48}$ Figure 4 a shows the overall micromorphology of single gold nanoparticles per vesicle diameter. Gold nanoparticles are seen in the blood cells easily, which is related to the size of the nanoparticles. Figure $4 \mathrm{~b}$ shows the transmission electron microscopy image of bone marrow cells, which is similar to that of blood cells. Many gold nanoparticles can be observed outside of the cell membrane, and the average size is about $10-15 \mathrm{~nm}$. Of note, the gold nanoparticles could still be found in blood and marrow bone cells after 14 days of oral administration, which indicates a long blood circulation time for gold nanoparticles, which is in good agreement with previous reports. ${ }^{38-40}$ It has been suggested that the interaction between protein and gold nanoparticles may be closely related to the toxicity of the nanoparticles. ${ }^{27}$ The surface of the citrate-stabilized gold nanoparticles probably contains a variety of serum proteins. Many of these serum proteins (eg, $\alpha$ and $\beta$ proteins)

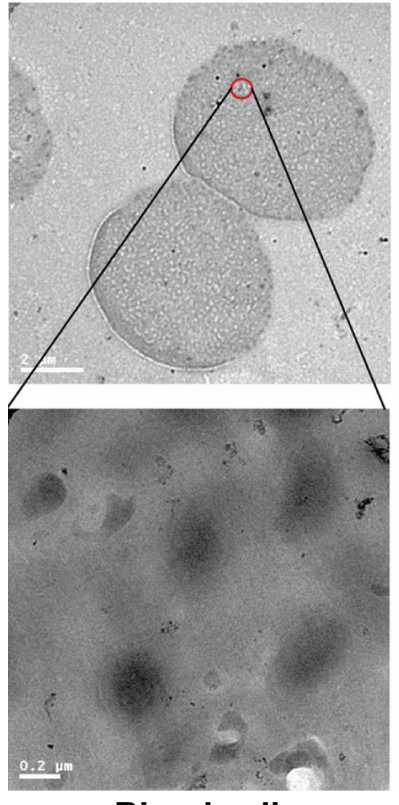

Blood cell

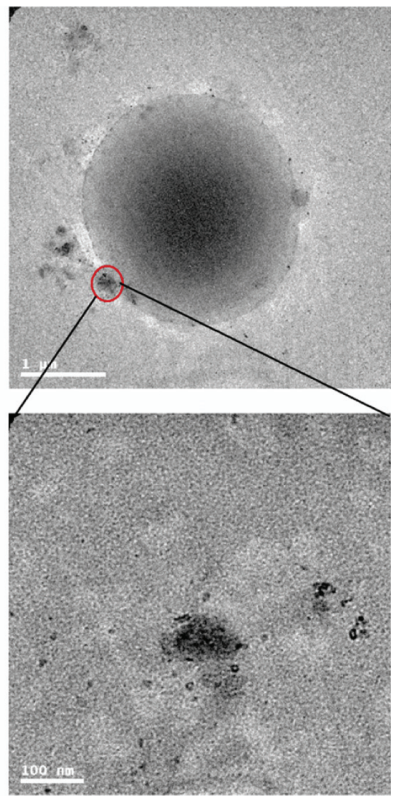

Bone marrow cell
Figure 4 Transmission electron microscopy figures for gold nanoparticles in bone marrow and blood cells 14 days after oral administration at $2200 \mu \mathrm{g} / \mathrm{kg}$. 
are known to be taken up by cells. ${ }^{48}$ It has been shown that gold nanoparticles strongly associate with essential blood proteins (such as albumin, fibrinogen, $\gamma$-globulin, histone, and insulin), and the degree of binding between the nanoparticles and proteins is increased, and that the degree of cooperativity of particles decreases with increasing size. ${ }^{49}$ Furthermore, these interactions, such as enhanced binding, can induce conformational change of the proteins. Thus, further study is necessary to understand how the mechanism of the protein adsorption process changes the protein conformation and the tendency for aggregation of gold nanoparticles.

\section{Organ indices and hematology results}

Table 2 gives the organ weights of mice at different nanoparticle doses to illustrate the effect of gold nanoparticles on organs. It can be seen that the weights of the heart, liver, spleen, lung, kidneys, and brain are decreased at the dose range $550-1100 \mu \mathrm{g} / \mathrm{kg}$. However, the weight of the thymus is increased with increases in nanoparticle concentration, but no statistically significant differences are found in these data. To further investigate the organ reaction, the organ indices for thymus and spleen are presented in Figure 5a. To examine the grade of changes explicitly caused by gold nanoparticles, the spleen and thymus indices $\left(\mathrm{S}_{x}\right)$ can be defined as:

$$
\mathrm{S}_{x}=\frac{\text { Weight of experimental organ }(m g)}{\text { Weight of experimental animal }(g)}
$$

The average values of thymus and spleen indices in the control group were 1.925 and 3.73 , respectively. The thymus and spleen indices in the treated group increased to 2.65 and 4.5 , respectively, at a gold nanoparticle dose of $2200 \mu \mathrm{g} / \mathrm{kg}$. There are still no statistically significant differences between the treated group and the control group, which shows that injections of gold nanoparticles at different doses do not cause obvious toxicologic effects on both the thymus and spleen. Table 3 shows the variations in organ weight and index by the different injection methods at the dose of $1100 \mu \mathrm{g} / \mathrm{kg}$. It can be seen that the weights of liver, lung, spleen, kidneys, and heart decrease according to the different injection routes. Some differences for brain and thymus weights were observed with oral administration. Thymus weight was slightly decreased with oral administration and tail vein injection, and slightly increased by intraperitoneal injection. However, these results showed no statistically significant difference. Figure $5 \mathrm{~b}$ gives the thymus and spleen indices after different injection routes. The thymus index shows little variation with the different injection routes. The spleen index is decreased by intraperitoneal injection and tail vein injection, and increased by oral administration. In particular, a statistically significant difference between the oral administration group and the control group is observed, which indicates that the immune system has been affected by oral gold nanoparticle administration. Taken together with the previous body weight variation, it seems that the oral administration route can affect the gastrointestinal system and furthermore can damage the immune system. Moreover, it implies that the spleen is one of the target organs for gold nanoparticles, which is in good agreement with previous work. ${ }^{32-42,50}$ The liver and spleen are considered two dominant organs for biodistribution and metabolism of gold nanoparticles. ${ }^{32-42}$

To quantify the toxicity of gold nanoparticles, the next important step is assessment of standard hematologic parameters, ie, platelet count, hematocrit, hemoglobin, red blood cell count, and white blood cell count.

Concentration-dependent hematology results are presented in Figure 6a. Hematocrit and red blood cells significantly decrease at gold nanoparticle doses of 550 and $1100 \mu \mathrm{g} / \mathrm{kg}$, respectively, but they do not indicate a

Table 2 Weight of organs for liver, lung, spleen, kidneys, brain, heart, and thymus after oral administration of different doses $(137.5-2200 \mu \mathrm{g} / \mathrm{kg})$ for 14 days

\begin{tabular}{lllllll}
\hline Dose $(\mu \mathrm{g} / \mathrm{kg})$ & Control & $\mathbf{1 3 7 . 5}$ & $\mathbf{2 7 5}$ & $\mathbf{5 5 0}$ & $\mathbf{I I 0 0}$ & $\mathbf{2 2 0 0}$ \\
\hline Heart $(\mathrm{g})$ & $0.194 \pm 0.048$ & $0.185 \pm 0.037$ & $0.167 \pm 0.057$ & $0.105 \pm 0.017$ & $0.104 \pm 0.027$ & $0.099 \pm 0.031$ \\
Liver $(\mathrm{g})$ & $\mathrm{I} .431 \pm 0.036$ & $1.437 \pm 0.433$ & $1.321 \pm 0.452$ & $1.206 \pm 0.197$ & $1.348 \pm 0.074$ & $1.071 \pm 0.012$ \\
Spleen $(\mathrm{g})$ & $0.120 \pm 0.004$ & $0.126 \pm 0.009$ & $0.160 \pm 0.068$ & $0.109 \pm 0.005$ & $0.103 \pm 0.047$ & $0.095 \pm 0.002$ \\
Lung $(\mathrm{g})$ & $0.305 \pm 0.060$ & $0.215 \pm 0.035$ & $0.246 \pm 0.052$ & $0.235 \pm 0.019$ & $0.140 \pm 0.040$ & $0.150 \pm 0.015$ \\
Kidneys $(\mathrm{g})$ & $0.215 \pm 0.048$ & $0.200 \pm 0.057$ & $0.221 \pm 0.054$ & $0.135 \pm 0.001$ & $0.135 \pm 0.011$ & $0.122 \pm 0.002$ \\
Thymus $(\mathrm{g})$ & $0.034 \pm 0.002$ & $0.067 \pm 0.011$ & $0.062 \pm 0.008$ & $0.054 \pm 0.013$ & $0.048 \pm 0.003$ & $0.056 \pm 0.01 \mathrm{I}$ \\
Brain $(\mathrm{g})$ & $0.391 \pm 0.028$ & $0.410 \pm 0.003$ & $0.389 \pm 0.043$ & $0.349 \pm 0.009$ & $0.370 \pm 0.045$ & $0.213 \pm 0.006$ \\
\hline
\end{tabular}

Data were analyzed by Student's t-test and the differences between the doses for each organ were not significant $(P>5 \%$ versus controls). All values represent the mean \pm standard deviation for six mice. 

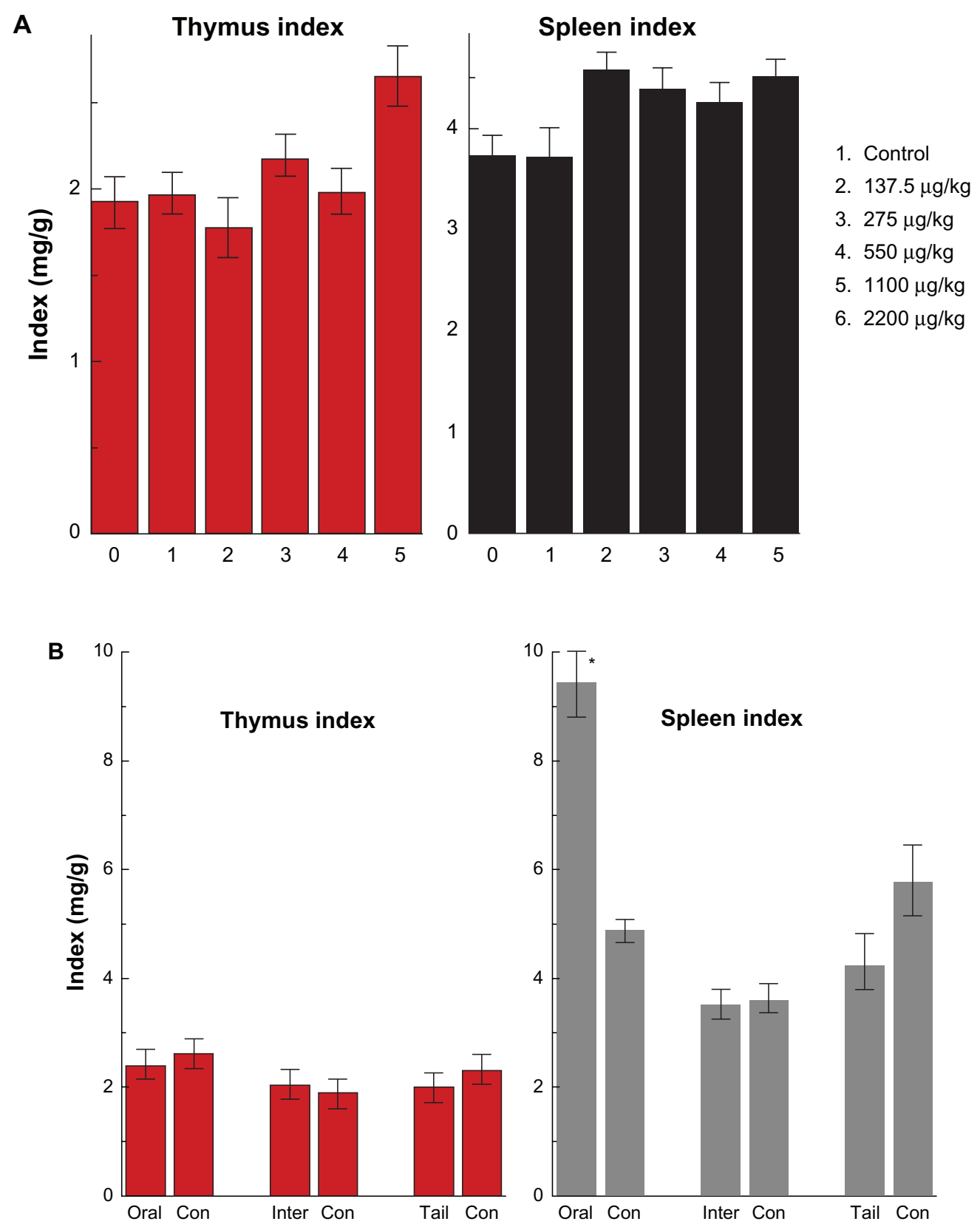

Figure 5 Thymus and spleen indices of mice after oral administration by different doses $(137.5-2200 \mu g / k g)(\mathbf{A})$ after 14 days and the different injection routes at the dose of $1100 \mu \mathrm{g} / \mathrm{kg}$ (B) after 28 days.

Note: All values are reported as means \pm standard deviation. Data were analyzed by Student's t- test. *Represents significant difference from the control group $(P<0.05)$. Abbreviations: ORAL, oral administration; INTER, intraperitoneal injection; TAIL, tail vein injection.

concentration-dependent trend associated with treatment. Hemoglobin, platelet count, and white blood cells have changed, but no statistically significant difference is observed. The hematologic effects of the different injection methods for the gold nanoparticles are shown in Figure 6b. It can be observed that hemoglobin, red blood cells, and white blood cells decrease with the three different injection routes, but the decrease was only statistically significant for red blood cells. This indicates that the different injection routes did not induce significant differences in platelet count, hemoglobin, or white blood cells. Red blood cells show a significant difference after oral administration, intraperitoneal injection, and tail vein injection. Oral administration and intraperitoneal injection induce a decrease in red blood cells, and the tail vein injection does not cause any significant change in this parameter.

Red blood cells are derived from hemopoietic stem cells in bone marrow. Following a series of maturation steps, directed 
Table 3 Weight of organs for liver, lung, spleen, kidneys, brain, heart, and thymus by using oral, intraperitoneal, and tail vein injection at doses of $1100 \mu \mathrm{g} / \mathrm{kg}$ at 28 days

\begin{tabular}{lllllll}
\hline $\begin{array}{l}\text { Dose } \\
(\mu \mathrm{g} / \mathrm{kg})\end{array}$ & $\begin{array}{l}\text { Control } \\
(\text { Oral) }\end{array}$ & $\begin{array}{l}\text { Oral } \\
\text { administration }\end{array}$ & $\begin{array}{l}\text { Control } \\
\text { (Intraperitoneal) }\end{array}$ & $\begin{array}{l}\text { Intraperitoneal } \\
\text { injection }\end{array}$ & $\begin{array}{l}\text { Control } \\
\text { (Tail vein) }\end{array}$ & $\begin{array}{l}\text { Tail } \\
\text { vein injection }\end{array}$ \\
\hline Heart $(\mathrm{g})$ & $0.195 \pm 0.025$ & $0.082 \pm 0.01 \mathrm{I}$ & $0.237 \pm 0.005$ & $0.222 \pm 0.005$ & $0.202 \pm 0.002$ & $0.132 \pm 0.058$ \\
Liver $(\mathrm{g})$ & $2.234 \pm 0.339$ & $1.329 \pm 0.177$ & $1.853 \pm 0.086$ & $1.832 \pm 0.176$ & $1.643 \pm 0.099$ & $1.157 \pm 0.226$ \\
Spleen $(\mathrm{g})$ & $0.176 \pm 0.042$ & $0.342 \pm 0.058$ & $0.129 \pm 0.042$ & $0.123 \pm 0.01 \mathrm{I}$ & $0.138 \pm 0.036$ & $0.061 \pm 0.003$ \\
Lung (g) & $0.278 \pm 0.049$ & $0.243 \pm 0.057$ & $0.521 \pm 0.022$ & $0.198 \pm 0.024$ & $0.209 \pm 0.078$ & $0.191 \pm 0.012$ \\
Kidneys (g) & $0.232 \pm 0.044$ & $0.162 \pm 0.028$ & $0.248 \pm 0.038$ & $0.237 \pm 0.068$ & $0.235 \pm 0.036$ & $0.182 \pm 0.009$ \\
Thymus $(\mathrm{g})$ & $0.095 \pm 0.020$ & $0.060 \pm 0.005$ & $0.036 \pm 0.006$ & $0.068 \pm 0.001$ & $0.076 \pm 0.008$ & $0.022 \pm 0.002$ \\
Brain $(\mathrm{g})$ & $0.411 \pm 0.014$ & $0.387 \pm 0.013$ & $0.437 \pm 0.002$ & $0.450 \pm 0.043$ & $0.412 \pm 0.025$ & $0.422 \pm 0.003$ \\
\hline
\end{tabular}

Data were analyzed by Student's t-test and the differences between the administration routes for each organ are not significant ( $P>5 \%$ versus controls). All values represent the mean \pm standard deviation for six mice.

mainly by erythropoietin, red cells enucleate and enter the circulatory system. Thus, the variation in red blood cells can be related to the hematopoietic system. Decreases in hematocrit and red blood cells are found at the high dose in Figure 6a. It can be determined that the high dose of gold nanoparticles can also have an obvious effect on the hematopoietic system. The in vitro toxicologic experiments indicate that the $10-100 \mu \mathrm{g} / \mathrm{mL}$ dose range is nontoxic for $13.5 \mathrm{~nm}$ naked gold nanoparticles, although the different cell lines may induce slight deviation..$^{20-26,43}$ The dose of gold nanoparticles in vivo $(137.5-2200 \mu \mathrm{g} / \mathrm{kg}$ ) is obviously lower than that in vitro. The difference in toxicologic effects between in vivo and in vitro systems is evident. In addition, the three routes of injection can produce different reactions in mice. Oral administration causes damage to the gastrointestinal system, and further affects the immune system via splenic metabolism. However, the detailed mechanism is still not clear and further study is necessary. All these abnormal responses in weight, spleen index, and red blood cells show that the oral administration route produces the highest toxicity compared with intraperitoneal and tail vein injection. For the intraperitoneal injection, the decrease in red blood cells still indicates damage to the hemopoietic system. The tail vein injection has the least effect on hematology, indicating the lowest toxicity. When gold nanoparticles are administered, the first physiologic system they interact with is the blood and its components. Indeed, gold nanoparticles can induce an inflammatory response and increase or decrease the activity of the immune system and alter related hematologic factors such as blood cell counts. ${ }^{51,52}$ Therefore, it is necessary to address these phenomena to reveal further

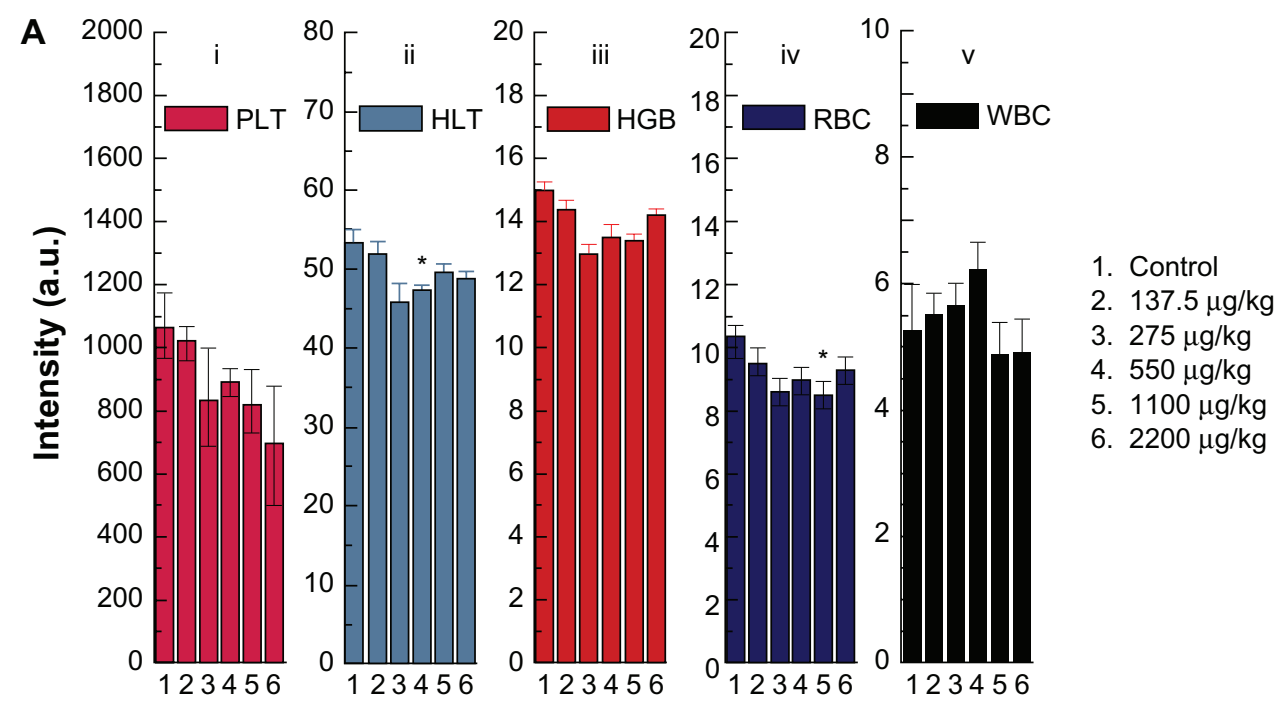

Figure 6a Hematology results from mice treated with gold nanoparticles and the control group after I4 days oral administration by different doses (I $37.5-2200 \mu \mathrm{g} / \mathrm{kg}$ ). Note: Bars represent mean \pm standard deviation. Data were analyzed by Student's t-test. *Represents significant difference from the control group $(P<0.05)$. Abbreviations: PLT, platelets; HCT, hematocrit; HGB, hemoglobin; RBC, red blood cells; WBC, white blood cells. 


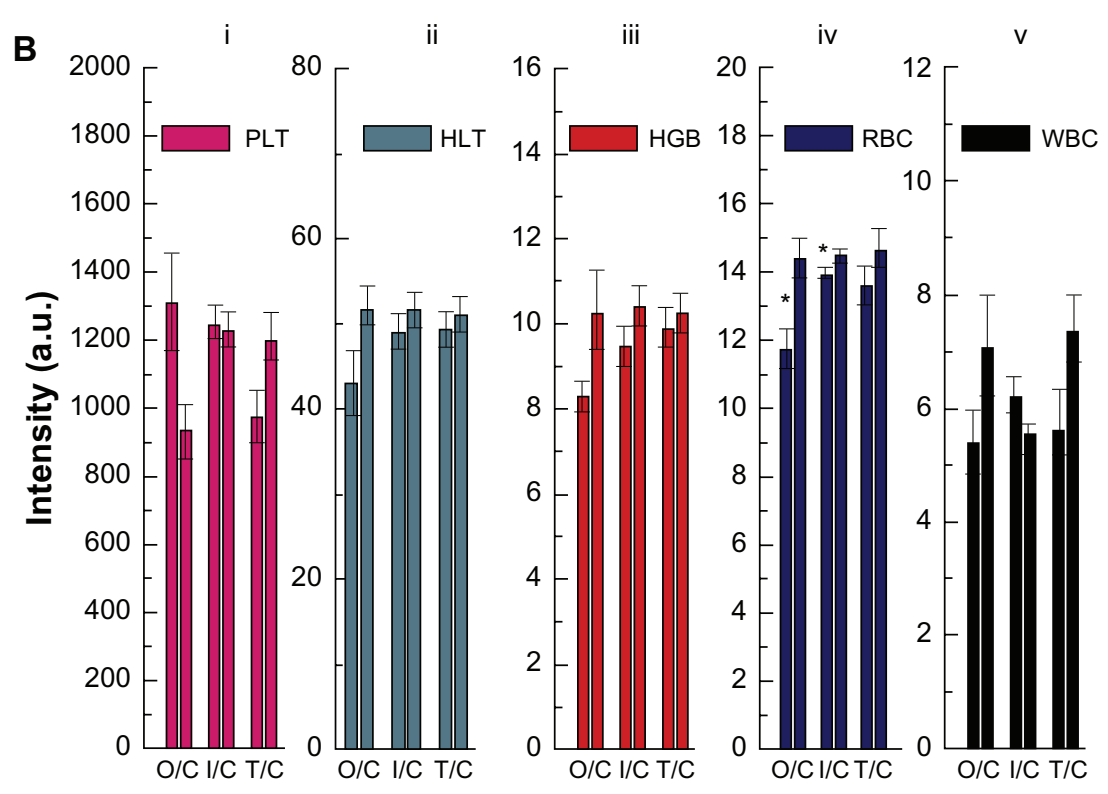

Figure 6b Hematology results from mice treated with gold nanoparticles and control groups after 28 days oral administration, intraperitoneal injection, and tail vein injection at the dose of $1100 \mu \mathrm{g} / \mathrm{kg}$.

Note: Bars represent mean \pm standard deviation. Data were analyzed by Student's t-test. *Represents significant difference from the control group $(P<0.05)$.

Abbreviations: PLT, platelets; HCT, hematocrit; HGB, hemoglobin; RBC, red blood cells; WBC, white blood cells; O/C, oral administration control; I/C, intraperitoneal injection/control; T/C, tail vein injection/control.

the mechanism of interaction between biologic tissue and gold nanoparticles in vivo.

\section{Conclusion}

An animal toxicity study using $13.5 \mathrm{~nm}$ gold nanoparticles in mice was carried out. Animal survival, animal mass, hematology, and morphology were characterized at different concentrations $(137.5-2200 \mu \mathrm{g} / \mathrm{kg})$ over 14-28 days. The results show that gold nanoparticles at low concentrations do not cause appreciable toxicity even after their breakdown in vivo over time. Increasing concentrations of gold nanoparticles induce decreases in weight but no significant statistical difference is observed. Obvious effects on organ index have been observed at high concentration. Moreover, of the three different administration routes, the oral and intraperitoneal injection show the highest toxicity, and tail vein injection shows the least toxicity. Considering the results of all of these studies, targeting gold nanoparticles by tail vein injection is promising for possible biomedical application.

\section{Acknowledgments}

The authors would like to thank Professor Liang-An Zhang, Shu-Yu Yuan, and Ti-Qiang Fan for supply of sample fabrications, measurements, and helpful discussions. This work was supported by the National Natural Science Foundation of
China (Grant No. 81000668), and the Specialized Research Fund for the Doctoral Program (SRFDP) of Higher Education State Education Ministry (Grant No.200800231058), and Subject Development Foundation of the Institute of Radiation Medicine, CAMS (Grant No. SF1003, SF0826).

\section{Disclosure}

The authors report no conflicts of interest in this work.

\section{Reference}

1. Danieland MC, Astruc D. Gold nanoparticles: Assembly, supramolecular chemistry, quantum-size-related properties, and applications toward biology, catalysis, and nanotechnology. Chem Rev. 2004;104: 293-346.

2. Eustis S, El-Sayed MA. Why gold nanoparticles are more precious than pretty gold: Noble metal surface plasmon resonance and its enhancement of the radiative and nonradiative properties of nanocrystals of different shapes. Chem Soc Rev. 2006;35:209-217.

3. $\mathrm{Hu}$ M, Chen J, Li ZY, et al. Gold nanostructures: Engineering their plasmonic properties for biomedical applications. Chem Soc Rev. 2006; 35:1084-94.

4. Anker JN, Hall WP, Lyandres O, Shah NC, Zhao J, van Duyne RP. Biosensing with plasmonic nanosensors. Nat Mater. 2008;7: $442-453$.

5. Sokolov K, Follen M, Aaron J, et al. Real-time vital optical imaging of precancer using anti-epidermal growth factor receptor antibodies conjugated to gold nanoparticles. Cancer Res. 2003;63: 1999-2004.

6. Link S, El-Sayed MA. Shape and size dependence of radiative, non-radiative and photothermal properties of gold nanocrystals. Int Rev Phys Chem. 2000;19:409-453. 
7. Pissuwan D, Valenzuela SM, Cortie MB. Therapeutic possibilities of plasmonically heated gold nanoparticles. Trends in Biotechnology. 2006;24:62-67.

8. Zheng J, Zhang C, Dickson RM. Highly fluorescent, water-soluble, size-tunable gold quantum dots. Phys Rev Lett. 2004;93(077402): $1-4$.

9. Huang X, El-Sayed IH, Qian W, El-Sayed MA. Cancer cell imaging and photothermal therapy in the near-infrared region by using gold nanorods. J Am Chem Soc. 2006;128:2115-2120.

10. Hainfeld JF, Slatkin DN, Smilowitz HM. The use of gold nanoparticles to enhance radiotherapy in mice. Phys Med Biol. 2004;49: N309-N315.

11. Juzenas P, Chen W, Sun YP, et al. Quantum dots and nanoparticles for photodynamic and radiation therapies of cancer. Adv Drug Deliv Rev. 2008;60:1600-1614.

12. Liu CJ, Wang $\mathrm{CH}$, Chien $\mathrm{CC}$, et al. Enhanced $\mathrm{x}$-ray irradiation-induced cancer cell damage by gold nanoparticles treated by a new synthesis method of polyethylene glycol modification. Nanotechnology. 2008; 19:295104-295109.

13. Nel A, Xia T, Mädler L, Li N. Toxic potential of materials at the nanolevel. Science. 2006;311:662-667.

14. Chen Z, Meng H, Xing G, et al. Acute toxicological effects of copper nanoparticles in vivo. Toxicol Lett. 2006;163:109-120.

15. Cho EC, Au L, Zhang Q, Xia Y. The effects of size, shape, and surface functional group of gold nanostructures on their adsorption and internalization by cells. Small. 2009;6:517-522.

16. Sayes CM, Reed KL, Warheit DB. Assessing toxicity of fine and nanoparticles: Comparing in vitro measurements to in vivo pulmonary toxicity profiles. Toxicol Sci. 2007;97:163-180.

17. Kim JS, Yoon TJ, Yu KN, et al. Toxicity and tissue distribution of magnetic nanoparticles in mice. Toxicol Sci. 2006;89:338-347.

18. Yang ST, Fernando KAS, Liu JH, et al. Covalently PEGylated carbon nanotubes with stealth character in vivo. Small. 2008;4: 940-944.

19. Goodman CM, McCusker CD, Yilmaz T, Rotello VM. Toxicity of gold nanoparticles functionalized with cationic and anionic side chains. Bioconjug Chem. 2004;15:897-900.

20. Connor EE, Mwamuka J, Gole A, Murphy CJ, Wyatt MD. Gold nanoparticles are taken up by human cells but do not cause acute cytotoxicity. Small. 2005;1:325-327.

21. Pernodet N, Fang X, Sun Y, et al. Adverse effects of citrate/ gold nanoparticles on human dermal fibroblasts. Small. 2006;2: 766-773.

22. Lewinski N, Colvin V, Drezek R. Cytotoxicity of nanoparticles. Small. 2008;4:26-49.

23. Murphy CJ, Gole AM, Stone JW, et al. Gold nanoparticles in biology: Beyond toxicity to cellular imaging. Acc Chem Res. 2008;41: 1721-1730.

24. Teeguarden JG, Hinderliter PM, Orr G, Thrall BD, Pounds JG. Particokinetics in vitro: Dosimetry considerations for in vitro nanoparticle toxicity assessments. Toxicol Sci. 2007;95:300-312.

25. Patra HK, Banerjee S, Chaudhuri U, Lahiri P, Dasgupta A. Cell selective response to gold nanoparticles. Nanomedicine. 2007;3: 111-119.

26. Male KB, Lachance B, Hrapovic S, Sunahara G, Luong HT. Assessment of cytotoxicity of quantum dots and gold nanoparticles using cell-based impedance spectroscopy. Anal Chem. 2008;80:5487-5493.

27. Chithrani BD, Ghazani AA, Chan WCW. Determining the size and shape dependence of gold nanoparticle uptake into mammalian cells. Nano Lett. 2006;6:662-668.

28. Pan Y, Neuss S, Leifert A, et al. Size-dependent cytotoxicity of gold nanoparticles. Small. 2007;3:1941-1949.

29. Manna S, Sarkar S, Barr J, et al. Single-walled carbon nanotube induces oxidative stress and activates nuclear transcription. Nano Lett. $2005 ; 5: 1676-1684$
30. Schipper M, Nakayama-Ratchford N, Davis C, et al. A pilot toxicology study of single-walled carbon nanotubes in a small sample of mice. Nat Nanotechnol. 2008:3:216-221.

31. Sayes C, Marchione Reed AK, Warheit D. Comparative pulmonary toxicity assessments of $\mathrm{C}_{60}$ water suspensions in rats: Few differences in fullerene toxicity in vivo in contrast to in vitro profiles. Nano Lett. 2007;7:2399-2406.

32. de Jong WH, Hagens WI, Krystek P, Burger MC, Sips AJAM, Geertsma RE. Particle size-dependent organ distribution of gold nanoparticles after intravenous administration. Biomaterials. 2008;29: 1912-1919.

33. Sonavane G, Tomoda K, Makino K. Biodistribution of colloidal gold nanoparticles after intravenous administration: Effect of particle size. Colloids Surf B Biointerfaces. 2008;66:274-280.

34. Kim JH, Kim KW, Kim MH, Yu YS. Intravenously administered gold nanoparticles pass through the blood-retinal barrier depending on the particle size, and induce no retinal toxicity. Nanotechnology. 2009;20:505101.

35. Chen YS, Hung YC, Liau I, Huang GS. Assessment of the in vivo toxicity of gold nanoparticles. Nanoscale Res Lett. 2009;4:858-864.

36. Cho WS, Kim S, Han BS, Son WC, Jeong J. Comparison of gene expression profiles in mice liver following intravenous injection of 4 and $100 \mathrm{~nm}$-sized PEG-coated gold nanoparticles. Toxicol Lett. 2009;191:96-102.

37. Semmler-Behnke M, Kreyling WG, Lipka J, et al. Biodistribution of 1.4- and 18-nm gold particles in rats. Small. 2008;4:2108-2111.

38. Cho WS, Cho M, Jeong J, et al. Acute toxicity and pharmacokinetics of $13 \mathrm{~nm}$-sized PEG-coated gold nanoparticles. Toxicol Appl Pharmacol. 2009;236:16-24.

39. Balasubramanian SK, Jittiwat J, Manikandan J, Ong CN, Yu LE, Ong WY. Biodistribution of gold nanoparticles and gene expression changes in the liver and spleen after intravenous administration in rats. Biomaterials. 2010;31:2034-2042.

40. Balogh L, Nigavekar SS, Nair BM, et al. Significant effect of size on the in vivo biodistribution of gold composite nanodevices in mouse tumor models. Nanomedicine. 2007;3:281-296.

41. Zhang G, Yang Z, Lu W, et al. Influence of anchoring ligands and particle size on the colloidal stability and in vivo biodistribution of polyethylene glycol-coated gold nanoparticles in tumor-xenografted mice. Biomaterials. 2009;30:1928-1936.

42. Lipka J, Semmler-BehnkeM, Sperling RA, et al. Biodistribution of PEG-modified gold nanoparticles following intratracheal instillation and intravenous injection. Biomaterials. 2010;31:6574-6581.

43. Zhang XD, Guo ML, Wu HY, et al. Irradiation stability and cytotoxicity of gold nanoparticles for radiotherapy. Int J Nanomedicine. 2009; 4:165-173.

44. Turkevich J, Stevenson PC, Hillier J. A study of the nucleation and growth processes in the synthesis of colloidal gold. Discuss Faraday Soc. 1951;11:55-75.

45. Hillyer JF, Albrecht RM. Gastrointestinal persorption and tissue distribution of differently sized colloidal gold nanoparticles. J Pharm Sci. 2001;90:1927-1936.

46. Jung T, Kamm W, Breitenbach A, Kaiserling E, Xiao JX, Kissel T. Biodegradable nanoparticles for oral delivery of peptides: Is there a role for polymers to affect mucosal uptake? Eur J Pharm Biopharm. 2000;50:147-160

47. Lasagna-Reeves C, Gonzalez-Romero D, Barria MA, et al. Bioaccumulation and toxicity of gold nanoparticles after repeated administration in mice. Biochem Biophys Res Commun. 2010;393:649-655.

48. Shenoy D, Fu W, Li J, et al. Surface functionalization of gold nanoparticles using hetero-bifunctional poly(ethylene glycol) spacer for intracellular tracking and delivery. Int $J$ Nanomedicine. 2006;1: $51-57$.

49. Lacerda SH, Park JJ, Meuse C, et al. Interaction of gold nanoparticles with common human blood proteins. ACS Nano. 2010;4:365-379. 
50. Sadauskas E, Danscher G, Stoltenberg M, Vogel U, Larsen A, Wallin H. Protracted elimination of gold nanoparticles from mouse liver. Nanomedicine. 2009;5:162-169.

51. Gjetting $\mathrm{T}$, Arildsen NS, Laulund $\mathrm{C}$, et al. In vitro and in vivo effects of polyethylene glycol (PEG)-modified lipid in DOTAP/ cholesterolmediated gene transfection. Int J Nanomedicine. 2010;5: 371-383.
52. Hauck TS, Anderson RE, Fischer HC, Newbigging S, Chan WCW. In vivo quantum-dot toxicity assessment. Small. 2010; 6:138-144.

53. Fent GM, Casteel SW, Kim DY, et al. Biodistribution of maltose and gum arabic hybrid gold nanoparticles after intravenous injection in juvenile swine. Nanomedicine. 2009;5:128-135.

\section{Publish your work in this journal}

The International Journal of Nanomedicine is an international, peerreviewed journal focusing on the application of nanotechnology in diagnostics, therapeutics, and drug delivery systems throughout the biomedical field. This journal is indexed on PubMed Central, MedLine, CAS, SciSearch $\AA$, Current Contents ${ } /$ Clinical Medicine,
Journal Citation Reports/Science Edition, EMBase, Scopus and the Elsevier Bibliographic databases. The manuscript management system is completely online and includes a very quick and fair peer-review system, which is all easy to use. Visit http://www.dovepress.com/ testimonials.php to read real quotes from published authors.

Submit your manuscript here: http://www.dovepress.com/international-journal-of-nanomedicine-journal 